\title{
Mérida, clave en la fundación de la Orden de Santiago
}

\author{
José Antonio Ballesteros Díez \\ UNED (C.A. MÉRIDA)
}

\section{RESUMEN ABSTRACT}

En este articulo se expone qué la razón por la cual la Orden de los Fratres de Cáceres se transformó en la Orden Militar de Santiago, a instancias del obispo de Compostela, radicó en que, a cambio de unos beneficios que éste concedió a Pedro Fernández, el maestre de los cacereños, la nueva Orden, en su avance reconquistador hacia el Sur, no deberia reclamar la restauración de la sede arzobispal de Mérida, trasladada interinamente a Santiago mientras su sede emeritense estuviera ocupada por los musulmanes.

\section{PALABRAS CLAVE}

Orden Militar de Santiago, Mérida, Arzobispado de Santiago de Compostela, repoblación.
In this article we are going to expose that the reason for wich the Order of the Fratres of Cáceres was transformed into the Military Order of Santiago at the request of the bishop of Compostela was possible because in exchange for some benefits that he gave Pedro fernández, the Knight of the cecereños, the new Orden in its reconquest advance to the South, shouldn't reclaim the retornation of the archiepiscopal see of Mérida, moved temporally to Santiago while it was occupied buy the Moslem.

\section{KEYWORDS}

Military Order of Santiago, Mérida, Archbishopric of Santiago de Compostela, repopulation.

\section{EL PRIMITIVO CRISTIANISMO EN MÉRIDA Y LA SEDE ARZOBISPAL}

La profunda transformación que han tenido los estudios historiográficos, especialmente en la segunda mitad del siglo $\mathrm{xx}$, cuando se ha pasado de lo puramente descriptivo a otros planos de análisis explicativo, tratando no sólo de conocer cómo se había manifestado un determinado proceso histórico, es decir, no sólo 
para percibir cómo se habian desarrollado unos acontecimientos, sino para saber qué es lo realmente sucedido, a qué causas se han debido esos hechos y que consecuencias se han producido, la vemos claramente refiejada en el proceso que aquí estudiamos, viendo cómo han afectado estos avances a unos conocimientos historiográficos que parecian solidamente fundamentados, como eran los origenes de la Orden Militar de Santiago.

El proceso que vamos a estudiar en este artículo requiere previamente que hagamos un breve recorrido por la historia del cristianismo en Mérida, que habia sido fundada como colonia romana el 25 a.C., siendo una ciudad que, por su importancia dentro del Imperio Romano, tenía, por una parte, la presencia de unas autoridades imperiales que fomentaban el politeísmo y que, por su propia posición preeminente, tendrian una gran influencia sobre la sociedad; de otra parte, la población emeritense era un conjunto multirracial, pues junto a los pobladores autóctonos del territorio estaban todos aquellos grupos que arrastraba, o atraía, la presencia de Roma por motivaciones políticas o mercantiles, lo que dificultaba que el enraizamiento del cristianismo en la Mérida hispano-romana tuviera que superar la dureza y sequedad de un terreno compactado por el politeismo, con dioses traídos del Mediterráneo oriental y cuyos cultos se celebraban con grandes y diversas fiestas, que iban desde bacanales hasta flagelaciones, o sacrificios sangrientos como los que se ofrecian en el culto de Mitra para ofrecer la iniciación a la virilidad ${ }^{1}$. Tenemos pues un cuadro complejo de distintas razas, culturas y religiones, a lo que contribuiria la presencia de gentes de origen griego, datada en el s. II, así como una comunidad hebrea, en lo que para algunos historiadores podría ser la comunidad judia más antigua en el solar hispano ${ }^{2}$, lo que quizá podría explicar que ello constituyera un foco de atracción para la temprana predicación del cristianismo, porque es verosimil pensar que los propagadores de la nueva fe buscaran los lugares con presencia hebrea para hacer su apostolado.

Habrá que esperar hasta el siglo III para tener documentos que testimonien fehacientemente la existencia de comunidades cristianas tanto en la Hispania romana como en la colonia Augusta Emerita, y ello se produce como consecuencia de la persecución de Decio, que en el año 250 promulgó un decreto obligando a todos sus súbditos a participar mediante los sacrificios establecidos en los cultos oficiales del Imperio romano; pocos años después, en el 257, Paternas, procónsul en Átrica, explicaba a Cipriano, obispo de Cartago, el contenido del edicto imperial que permitía la persecución a los cristianos: "Eos qui Romariam religionem non colunt, debere debere Romanas caeremonias recognoscere" (Aquellos que no profesan la religión romana no deben rehusar el tomar parte en las ceremonias religiosas romanas) ${ }^{3}$, el cumplimiento de este mandato se certificaba por las autoridades me-

Rodriguez Moñino, A.: Historia literaria de Extremadura. Badajoz, 2003, pgs, 23 a 40.

2 Gafcia IGlesias, L.: "Judios en la Mérida romana y visigoda". Revista de Estudios Extremeños, Tomo $\times X X I$, Num. I., Badajoz, 1976, pgs. 79 a 98.

ST. Crolx: "Why where the early christians persecuted". Studies in Ancient Society (Ed. M. Finley). Londres, 1974, pg. 248. 
diante un documento, el libelo, expedido a nombre de los participantes en los cultos, que les garantizaba su seguridad personal. Para los cristianos, el acatar el decreto imperial mediante la participación en los cultos oficiales suponía la apostasía, y asi muchos de ellos se negaron a obedecer tal mandato, lo que fue castigado como prescribía el edicto del Emperador, mientras algunos otros que consiguieron, más o menos fraudulentamente, el libelo obtuvieron así la seguridad para sus personas; a éstos se les conoció como libeláticos, y entre ellos estaban Marcial obispo de Mérida, y Basilides, obispo de Astorga-León.

No se conoce cual era la importancia numérica de los cristianos entre la población emeritense de aquellos momentos, pero si hay testimonios de que constituían una comunidad muy activa en la defensa de su fe, tanto frente al paganismo oficial como frente a los que se desviaban de los preceptos religiosos del cristianismo, como fue el caso de los libeláticos, que con su comportamiento crearon una situación de cisma en la comunidad de creyentes, de tal modo que el conflicto rebasó el ámbito clerical y estuvo asumido por la comunidad eclesial que llegó a recurrir a la autoridad de Cipriano para que esclareciese el asunto, pues esta comunidad cristiana consideraba como apostata a su obispo Marcial, al que depondría eligiendo a Félix como sucesor, en el entendimiento de que tenía ese derecho por tradición apostólica y estaba facultada tanto para elegir como para recusar a sus obispos ${ }^{4}$.

La respuesta del obispo de Cartago, el que luego fuera San Cipriano, dirigida a las iglesias de León, Astorga y Mérida, es el primer documento en la Historia de España que muestra la existencia de una comunidad religiosa organizada y jerarquizada en la Península Ibérica; y por esa carta sabemos también de la existencia de una autoridad episcopal en Mérida.

Esta carta ${ }^{5}$ ha sido datada entre los años 254 , fecha de la elección del papa Esteban I, y 258, año de la muerte de San Cipriano, mártir de la fe que lo alzaría a la santidad. Aparte de atender a dar respuesta a la licitud o ilicitud del ministerio pastoral de los obispos libeláticos, el texto informa de la existencia de una organización eclesial, con su jerarquía, con una normativa para la elección de obispos, y de la configuración de una circunscripción territorial, la provincia eclesiástica, cuyos obispos han intervenido en la elección de Félix, para Mérida, y Sabino, para Astorga, en sustitución de los libeláticos.

El padre Flore ${ }^{6}$ dice que «no se debe dudar que Mérida tuvo obispo en el espacio muy cercano a los primeros Varones Apostólicos", y aunque el primer obispo del que se tiene memoria histórica es del libelático Marcial, según la carta de San Cipriano, no se puede probar que fuera el primero.

\footnotetext{
4 Camacho Macias, A.: "La sede emeritense y su proyección histórica". VV.AA: Historia de la Baja Extremadura. Tomo I. Badajoz, 1986, pgs.230 a 279.

5 Moreno de Argas, B.: Historia de la ciudad de Mérida. Madrid, 1633, is 770 a 800 (Texto latino de la carta)

- Florez, E.: España Sagrada. Tomo XIII, Madrid, 1782, pag. 132
} 


\section{ESPANA SAGRADA,}

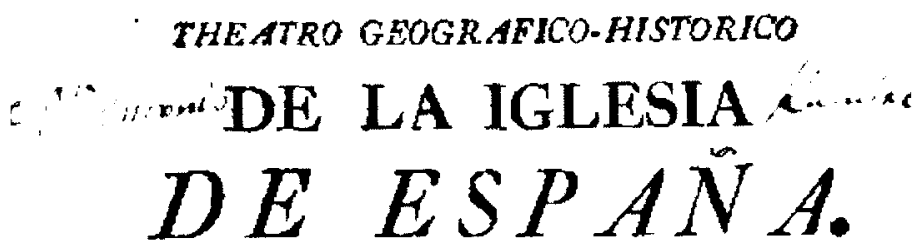

ORIGEN , DIVISIONES , Y LIMITES DE TODAS

sus Provincias. Antiguedad, Trastaciones, y estado antiguo y presente de sus Sillas, con varias

Disertaciones criticas.

TOMO XIII.

DE LA LUSTTANIA ANTIGUA EN COMUN, $y$ de su Metropoli Mérida en parsiculat.

EDICION SEGUNDA.

Dedicado d las Santos de esta Metropoli.

Por el R. P. M. F. Henrique Florex, Doftor y Catbedratice de Tbeologla de la Unicersidad de Allcalá, y Ex-Asistemte

General de las Provinaias de Espuña, Orden de N.P.S. Agustin, Éc.

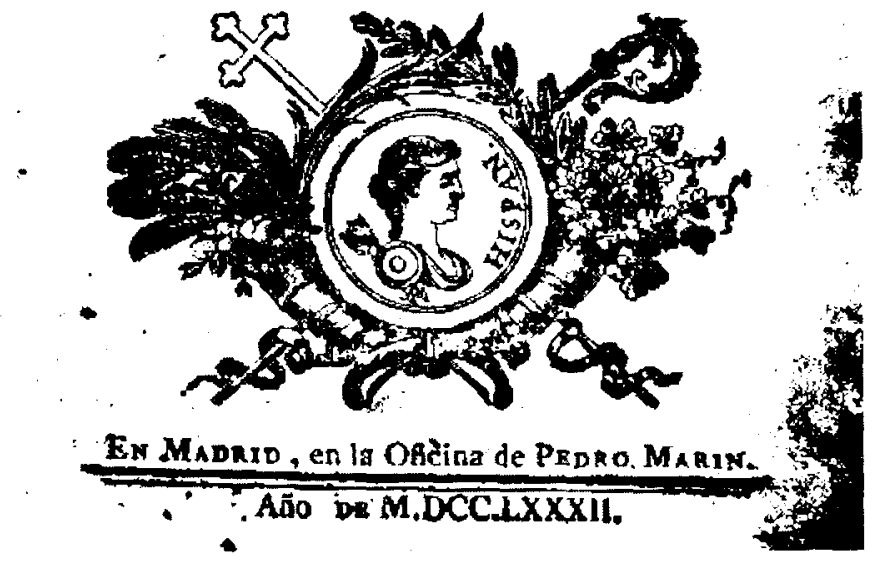

Para algunos historiadores, el hecho de que la comunidad cristiana emeritense se dirija al obispo de Cartago para exponerle sus problemas, en lugar de hacerlo al pontífice romano, muestra que el origen del cristianismo en este territorio de la Lusitania era el de la iglesia norteafricana, con la que indudablemente se mantendrían relaciones y vínculos afectivos que pervivieron durante mucho tiempo, pues años después, ya en el siglo iv, tras la persecución de Diocleciano que llevó al martirio a varios emeritenses, y entre ellos a Eulalia, santa que figuraría en el 
martiriológio de Cartago, a la que, además, San Agustín ${ }^{7}$ le dedicaría un sermón el día de su festividad, y cuyo martirio fue cantado por Aurelio Prudencio en el Himno IIl del Peristephanon, a comienzos del siglo v.

Del siglo Iv se conoce la asistencia de los obispos emeritenses a concilios diversos, como el de lliberis, el primero del que se tiene noticia y que se conoce como Concilio de Elvira, y en cuyas actas aparece como firmante el obispo de Mérida Liberio, el cual participó también en el concilio de Arlés del año 314. Pero en esta centuria, conflictiva y complicada, el hecho más sobresaliente de la Iglesia en Mérida sería el de los martirios que ocasionó la persecución de Diocleciano, destacando el de Santa Eulalia, en el año 304, que alcanzó una gran resonancia en el mundo cristiano, no sólo en Hispania, sino en la Galia ${ }^{8}$ y en el Norte de África, a lo que contribuyó el hecho de que Mérida fuese la sede del Vicariato Hispánico.

El cristianismo, que ya habia penetrado en la trama social del Imperio Romano, y que demostró la fortaleza de su creencia en las persecuciones, fue aceptado oficialmente con el Edicto de Milán (313), momento desde el que se producirá una sustitución de las antiguas divinidades paganas por las figuras de los mártires y de los obispos, lo que supuso para la iglesia emeritense pasar al primer plano, no sólo de la Hispania cristiana sino del ámbito cristiano en general, como evidencia que Santa Eulalia, junto a San Vicente, el mártir de Valencia, sean los únicos santos hispánicos que figuren en los mosaicos de San Apolinar, en Rávena, del siglo vI.

El Concilio de Nicea, del año 325, será el que marque la organización territorial de la Iglesia, perfilando la provincia eclesiástica como unidad superior a la diócesis, y será el papa Inocencio I el que disponga, en el año 415, que los límites territoriales de toda provincia eclesiástica deberian coincidir con los de las antiguas circunscripciones político-administrativas del ámbito civil. Paralelamente al Vicariato Hispánico establecido en Mérida, el papa Simplicio (468-483), se dirigía al obispo Zenón en la sede emeritense con estas palabras: «Simplicio al querido hermano Zenón: Por referencia de muchos hemos sabido que tu amor, con el fuego del Espiritu Santo, te ha constituido en tal gobernante de tu Iglesia que ésta, por permisión de Dios, no se resiente de los desastres del naufragio. Gloriándonos por ello en tales pruebas, hemos juzgado oportuno confiarte la autoridad vicaria de nuestra

Morin, G.: "Una page inedite de Sainte Augustin : Sermo de die sante Eulalie". Revue Benedictine, 8 (1892), pag, 417 y siguientes (Cita tomada de A. Camacho Macias: "La sede emeritense», ob, cit. Pag. 270)

- Mateos Martín de Rodrigo, A.: Santa Eulalia de Mérida. Mérida, 2004, pg. 199. Esta obra demuestra la extensión que alcanzó la devoción y culto a Santa Eulalia fuera de las fronteras de Hispania, y como hito importante cita la "Cantilene de sainte Eulalie", composición poética escrita a finales del siglc XII y que se considera la primera obra escrita en francés: Roger BERGER y Annette BRASSEUR: LeS Sequences de sainte Eulalie: Droz. Geneve, 2004, pg. 8; y aun llega más lejos Glanville Price: "La Cantileene de sainte Eulalie et le probleme du vers 15". Actes du colleque de Valenciennes. Ed. M-P. Dion,. Valenciennes, 1990 , pgs. 81 a 88 , donde dice: "no se exagera al afirmar que, desde los puntos de vista tanto lingüistico como literario, la Cantilena de Santa Eulalia constituye el más viejo texto no solamente francés sino también romance que ha llegado hasta nosotros. Se trata del más viejo poema romance, del más viejo texto literario romance, no importa en que lengua nacida del latin"s. 
Sede, para que de tal poder investido no permitas transgredir los decretos de la disciplina Apostólica ni los preceptos de los Santos Padres, porque ha de acumularse esta digna recompensa de honor en aquel por quien se sabe ha crecido el culto divino en esas regiones" ${ }^{9}$.

La irrupción de los pueblos bárbaros en Mérida a lo largo del siglo v suponia la llegada de paganos y luego de arrianos. Los godos, arrianos, llegaron en tiempos de Eurico (466-484) y coexistieron con la comunidad católica, teniendo cada cual su propia jerarquia eclesiástica, pero en el siglo vi, durante el reinado de Leovigildo era obispo católico de Mérida Masona, un visigodo, hombre de gran personalidad al que Leovigildo intentó repetidamente que abrazase al arrianismo como paso previo a una unificación religiosa en el reino, pero Masona defendió la ortodoxia cristiana lo que le llevó al destierro por orden del rey, y a su vuelta sería el hombre clave en la conversión del Recaredo al catolicismo.

La Provincia Eclesiástica era el ámbito jurisdiccional del metropolita o arzobispo, y en lo que respecta a Mérida su provincia comprendia diócesis de origen romano (Ävila, Evora, Lisboa y Faro), de origen suevo (Viseo, Coimbra, Idanha y Lamego) y de origen visigodo (Coria, Beja y Salamanca). La historia de la Provincia Eclesiástica emeritense está llena de incidentes, unos de orden puramente eclesiástico y otros por influencia de los cambios políticos que se sucedieron con las invasiones de los pueblos germánicos, y asi, mientras los suevos respetaron la capitalidad de Mérida como sede del Vicariato Romano, sin embargo los visigodos establecerían su capitalidad en Toledo.

En el siglo IV las sedes metropolitanas hispanas, es decir, las que encabezaban una provincia eclesiástica, eran Sevilla, Cartagena, Braga-Lugo, Tarragona y Mérida. En el siglo VII, en el reino visigodo, ya había 82 obispados, distribuidos en seis provincias eclesiásticas (Galia, Galicia, Tarragona, Cartagena, Sevilla y Mérida); el mapa que representamos es reproducción de uno que expone José Luis Martín ${ }^{10}$.

Sin duda, los hechos de mayor gravedad en la historia de la sede metropolitana emeritense fueron los derivados de la ocupación por los musulmanes, que llevaron a la desaparición de la sede episcopal, y después, a la fuerte presión, incluso con sobornos, que el obispo Gelmirez, de Santiago de Compostela, ejerció sobre los papas y la curia romana, primero para que le concediesen el pallium, símbolo de la dignidad arzobispal, y después para dotar a esa dignidad de su correspondiente provincia eclesiástica, lo que requería sustraer a otra provincia algunas diócesis sufragáneas, o asignarle al obispo compostelano la dignidad que antes poseyó otra iglesia; y tras diversos e infructuosos intentos para conseguir los derechos de Braga, el obispo Gelmirez acometió nuevas gestiones para que le adjudi-

9 Traducción del texto latino de J. SAENz DE AGUIRRE: “Collectiop máxima Conciliorum Hispaniae" III. Roma, 1753, pag. 120 a 122. Regesta Pontificium Romanorum. Leipzig, 1885, pg. 83. (Cita tomada de A. Camacho Macias: El libro de la vida de los Santos Padres de Mérida. Mérida, 1988).

10 Martin, J. L.: Manuel de Historia de España. Vol. 2. La España medieval. Marid, 1993, pg. 192-192. 


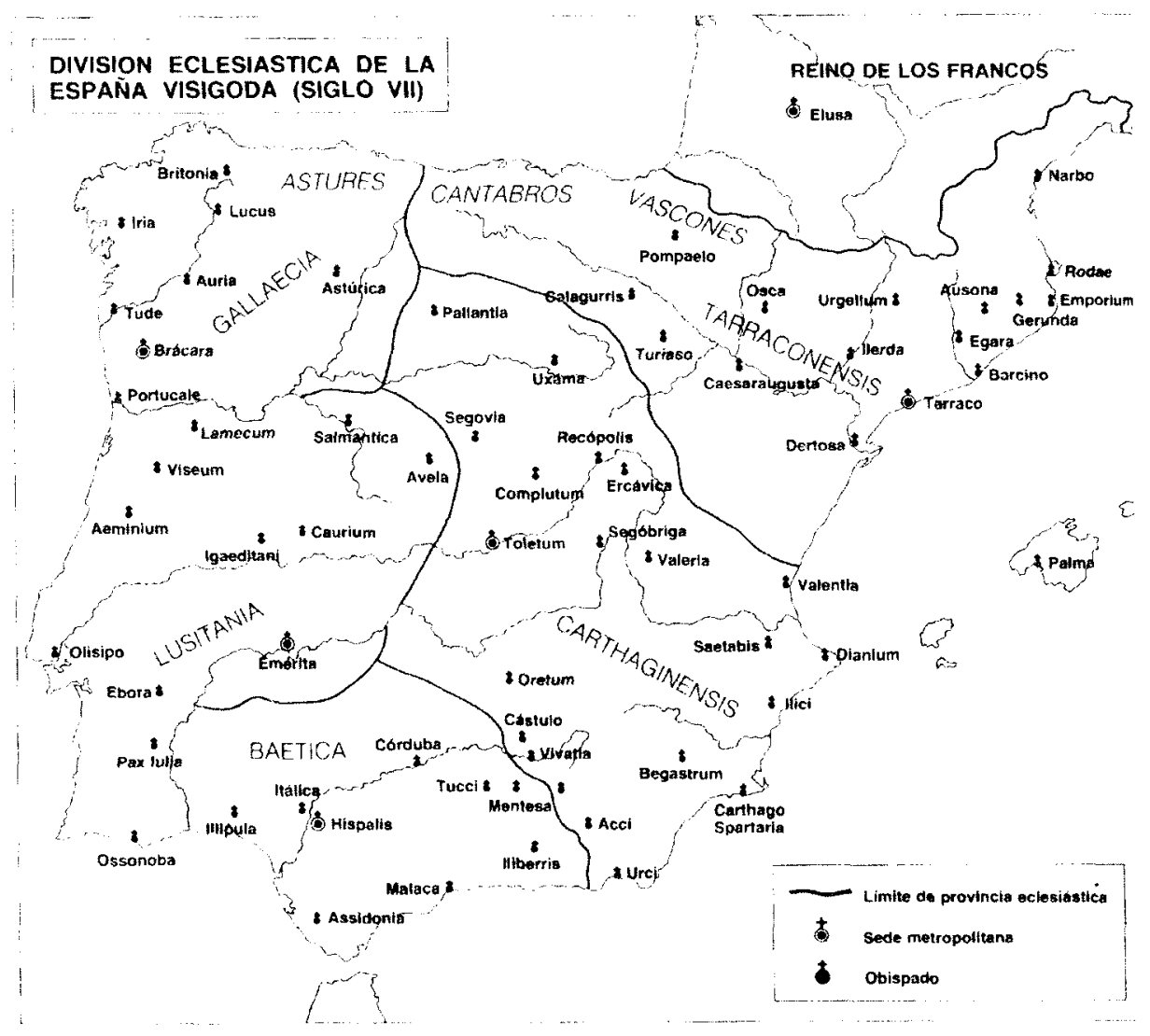

caran los derechos metropolitanos de Mérida, aun bajo el dominio del Islam, lo que conseguiría mediante la bula del papa de 27 de febrero de 1120, por la que se le adjudicaba esa dignidad de la Iglesia de Mérida a título personal y chasta tanto la ciudad fuese reconquistada"; posteriormente, en 1124, conseguiría otra bula que confirmaba el traslado de tales derechos sin ninguna limitación.

Antes de cerrar este apartado sobre la historia de la sede episcopal de Mérida, es de resaltar que la iglesia emeritense, aparte de la influencia positiva que recibe de la mayor importancia política y administrativa de la ciudad en el ámbito imperial hispano-romano, se va a caracterizar, desde su origen, por una defensa de la práctica religiosa cristiana dentro del marco de la ortodoxia, y así lo testimonian el episodio del obispo libelático Marcial, y años después, en el siglo Iv, cuando se produce el fenómeno del priscilianismo, que si en la práctica personal se ceñia a un acentuado rigorismo, en el aspecto doctrinal caía en un maniqueísmo, y asi sus seguidores se consideraban elegidos e inspirados directamente por Dios. Esta co- 
rriente religiosa afectó intensamente a la comunidad cristiana de Mérida, pues se ha supuesto por algunos historiadores que Prisciliano seria un seglar emeritense de los que había estado en conflicto con su obispo Hidacio; Prisciliano fue ordenado y consagrado por dos obispos del movimiento heterodoxo: Instancio y Salviano, pero el obispo de la sede emeritense, Hidacio, consiguió sofocar el foco priscilianista y expulsar a sus seguidores de las tierras lusitanas. Años después se reintegraron a la autoridad del metropolitano emeritense los obispos sufragáneos que había seguido a Prisciliano, que se supone fueron los de Salamanca y Coria. Fueron también las actuaciones del obispo Masona otras muestras de cómo la iglesia emeritense luchó siempre por la defensa y mantenimiento de la ortodoxia cristiana, lo que contribuía al prestigio de la sede emeritense.

\section{LA FUNDACIÓN DE LA ORDEN DE SANTIAGO}

Tras la ocupación en el año 711 de la Península lbérica por los ejércitos musulmanes, la ciudad de Mérida cayó bajo el dominio de Muza el 30 de Junio del 713; muy poco después, probablemente el 718, se iniciaba un levantamiento de los cristianos en Asturias oponiéndose al empuje de los islámicos y dando origen a ese proceso histórico que conocemos como Reconquista, y que estuvo indisolublemente unido, como las dos caras de una moneda, a otro proceso histórico, el de la repoblación por los cristianos de los terrenos reconquistados.

La puesta en marcha de estos procesos manifiestan las diversas mentalidades y objetivos que animaban a los cristianos en ese enfrentamiento con los musulmanes, y asi, mientras unos pretendian servir a ideales religiosos, o patrióticos, para la recuperación del dominio sobre el solar hispano, otros iban en pos de logros materiales, como la posesión de tierras o de ganados; incluso con el paso del tiempo, y fue muy largo este proceso, también cambiaron las motivaciones de los que se incorporaban a estas actividades reconquistadoras, y si al principio eran muchos los que participaban, conforme iban desplazando hacia el Sur la frontera con el Islam se aumentaba el territorio cristiano y se consolidaban núcleos de población estables, formándose comarcas y regiones en donde se asentaban permanentemente pobladores que habian contribuido al avance militar, cuya actividad abandonaban para vivir sedentariamente en tareas agrícolas y ganaderas, así como otros que procedian de tierras norteñas repobladas con anterioridad y de las que salian como excedentes de población en la búsqueda de condiciones mejores de vida; población que al disponer de tierras para labrar en su propio provecho se desentendia paulatinamente de la guerra y creaba un problema de falta de efectivos humanos para continuar la lucha frente a los musulmanes.

Durante el siglo xII la batalla por el dominio territorial de la actual Extremadura no era sólo contra los musulmanes, pues también el monarca portugués Alfonso I, con a ayuda del aventurero Geraldo Sempavor, consiguió las plazas de Cáceres y Trujillo en 1165, y la de Montánchez en 1166, y con ello establecía una cuña entre 
españoles y musulmanes que, a la vez, era una barrera que obstaculizaba la expansión leonesa hacia el Sur siguiendo el curso de la vieja Vía de la Plata e impedía el aprovechamiento de los pastos de las tierras extremeñas por los ganados trashumantes. Además de estas circunstancias se daba también el hecho en el reino de León de que, mientras Castilla y Portugal contaban respectivamente con las sedes metropolitanas de Toledo y Braga, la sede compostelana habia obtenido sus derechos por traslado de los de Mérida y si esta ciudad era reconquistada por castellanos o portugueses reclamarían indudablemente la restauración de sus derechos episcopales y ello supondría a los eclesiásticos leoneses pasar a depender de Toledo o de Braga. Circunstancias económicas y eclesiásticas espolearon a los leoneses para acometer la reconquista de los territorios extremeños, empezando por los que controlaban los portugueses, para cuya campaña el monarca Fernando II buscó la ayuda de los almohades, consiguiendo la recuperación de Cáceres y Badajoz en 1169.

Esta guerra de Reconquista fue presentada, y asumida, en la Cristiandad como una Cruzada, y ello propició que participaran caballeros francos que ayudaron en el empuje de los cristianos hispanos, pero a mediados del siglo XII ya dejaron de venir a guerrear a España, donde, por otra parte, ahora se sufría un importante rearme de los musulmanes, que con los almohades volverían a recuperar tierras y a producir fuertes embates a los núcleos de población cristianos. Los monarcas de los reinos cristianos españoles creyeron que para resolver esa deficiencia de fuerza militar podrían disponer de las ordenes militares de los templarios y los hospitalarios, pero sus maestres insistian en que la única finalidad de sus ordenes era defender Jerusalem y se negaron a combatir en España; tendría que ser el abad Raimundo, del monasterio cisterciense de Fitero, el que organizase una hermandad religiosa, en 1158, según la regla cisterciense, con voluntarios dispuestos para combatir contra los musulmanes. El papa Alejandro III aceptaría la nueva orden, y aprobaria su regla en 1164; habia aparecido la primera orden militar española ${ }^{11}$, que poco después pasaría a ser conocida como la Orden de Calatrava.

La formación de estos nuevos instrumentos para fortalecerse en la defensa de los ataques musulmanes, primero, y proseguir la Reconquista, en segundo lugar, movilizó de nuevo al obispo compostelano, pues a pesar de las bulas conseguidas por Gelmirez que confirmaban el traslado de la dignidad metropolitana de Mérida a Santiago, siempre tenía en su horizonte la posibilidad de que se restaurase en Mérida su antigua dignidad eclesiástica una vez estuviera de nuevo la ciudad y su territorio en poder de los cristianos, y asi empezó activamente a trabajar cerca del rey Alfonso VII, del que obtuvo la promesa de que le daría el dominio y la jurisdicción de la ciudad de Mérida cuando fuese reconquistada; no obstante, para mayor seguridad, el arzobispo don Pedro, en 1170, recabó del nuevo monarca Fernando Il la confirmación de esa promesa.

1 Lomax, D. W.: La Reconquista. Barcelona, 1984. pgs. 142-144. 
Pero las acciones del obispo compostelano no se reducian a las gestiones en la corte del monarca leonés, pues, en otra línea, se dirigían hacia los freires de Cáceres, una congregación recién fundada por Pedro Fernández de Fuente Escalada, su maestre, con el que llegó al acuerdo de transformar esa nueva institución, llamada de los Fratres de Cáceres, en la Orden Militar de Santiago, a la que el obispo compostelano regaló una bandera, hizo canónigo de Santiago al maestre Fernández y además le concedió diversas donaciones. José Luis Martín ${ }^{12}$ da la fecha del 1 de Agosto de 1170 como la de creación oficial de la Orden de Santiago, y señala que el primer documento conservado de la Orden, de Febrero de 1171, nos informa de que el arzobispo de Santiago dio nombre y hábito a los nuevos caballeros, pero no hace ninguna mención en relación a los verdaderos intereses que movian al arzobispo compostelano a fomentar esa organización eclesiástico-militar, muy alejados del ámbito espiritual y de la lucha contra los musulmanes.

La bula fundacional de la Orden de Santiago fue concedida por el papa Alejandro III el 5 de Julio de $1175^{13}$, y en ella le confirmaba sus propiedades y eximía a sus caballeros de la tutela episcopal.

El décimo tercer maestre santiaguista fue don Pedro Alonso, hijo bastardo del monarca leonés Alfonso IX, y ambos prosiguieron con sus fuerzas la reconquista de las tierras de la actual Extremadura, y tras un asedio ocuparon Mérida en 1230, en cuya conquista estuvo presente don Bernardo, el arzobispo de Santiago de Compostela, quien desde el momento de poner pie en la ciudad se opuso firmemente a las pretensiones de algunos de solicitar la restauración de la que había sido sede primada de la Iglesia en Hispania. El rey Alfonso el Nono hizo merced de la ciudad al arzobispo, el día 2 de Junio de 1230, confirmando expresamente lo que habian prometido sus reales antecesores y otorgando el privilegio correspondiente ${ }^{14}$.

Tras la muerte del maestre Pedro Alonso, fue elegido sucesor en la dignidad maestral, precisamente en Mérida, don Pedro González Mengo, el cual aprovechó las dificultades que tenia el arzobispo de Santiago para defender Mérida, como le incumbía, y consiguió de él un acuerdo por el cual la Orden santiaguista se haría cargo de la defensa de la ciudad y su territorio a cambio de que el arzobispo cediera a la Orden la mitad de la ciudad, con sus términos y rentas correspondientes, pero sin participar en la jurisdicción eclesiástica que aquel se reservaba por completo. Este pacto ${ }^{15}$, formalizado el 13 de Abril de 1231, se establecia por un plazo de cuatro años, durante cuya vigencia el arzobispo podia devolver su parte al rey o bien retenerla, pero nunca perder su autoridad espiritual sobre la ciudad.

12 Martin, J. L.: Origenes de la Orden Militar de Santiago (1170-1195). CSIC Barcelona, 1073, pgs. 11 a 19

13 Lomax, D. W.: La Orden de Santiago (1170-1275). CSIC. Madrid, 1965, pgs. 23 y 24.

1 AHN: Ordenes. Uclés. 198, Vol I. Num. 1. El texto está completo en B. MORENO DE VARGas: Historia de la ciudad de Mérida. Madrid, 1633. fs. 228 a 229.

15 AHN: Ordenes. Uclés, 198, Vol. I, num. 4. Dato tomado de J. V. Matellanes Merchan: La Orden de Santiago y la organizacion social de la Transierra castellano leonesa (SS. XII-XIV). Cuadernos de Historia Medieval. Monografías. 1 (1999), pgs. 78 y 79. 


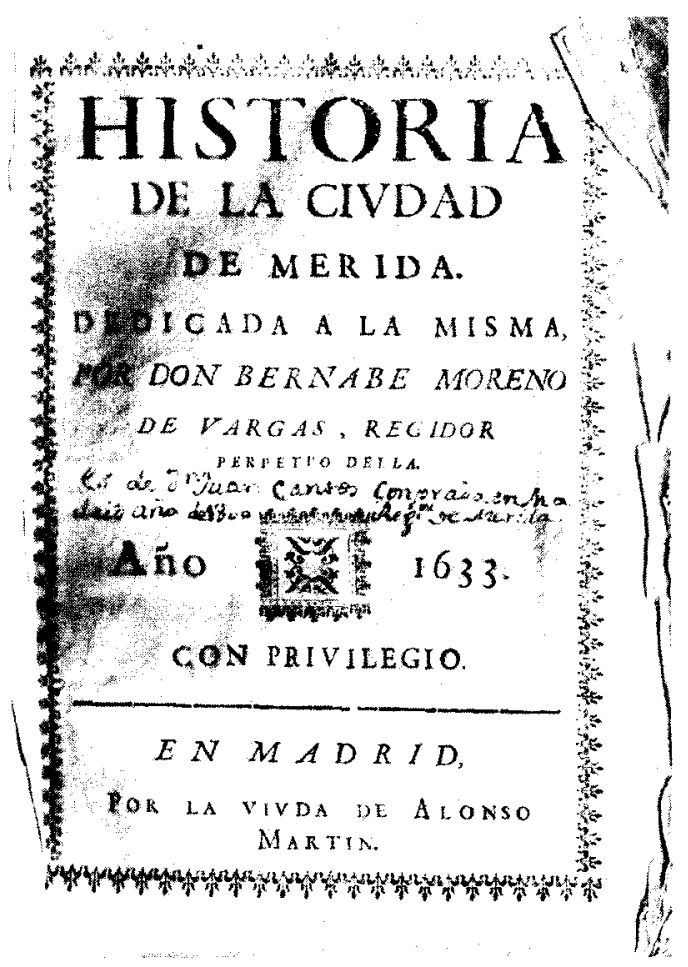

Esta cesión de la mitad de Mérida a los santiaguistas fue, en expresión de José Luis Martin ${ }^{16}$, "una jugada maestra del eclesiástico compostelano", porque a la vez que se desentendia de su defensa militar, con los gastos y problemas e incomodidades que esto suponia, se aseguraba que en ella no habría posibilidad de sostener una sede episcopal, porque al conceder la mitad de los frutos y diezmos de las iglesias a la Orden, mientras la sede compostelana se reservaba la otra mitad, se anulaba la fuente de ingresos para la iglesia emeritense; y, además, al mantener reservados todos los derechos en el ámbito espiritual, el futuro eclesiástico de Mérida quedaba absolutamente sometido a la sede compostelana.

Pero la fuerza de la tradición histórica de la sede emeritense seguía teniendo alguna efectividad, y no cesaban las peticiones para la restauración de su antigua dignidad, lo que llegó hasta el punto de que el propio papa decidiera el nombramiento de un obispo para Mérida, eligiéndose a don Alonso, a la sazón porcionero de Santiago de Compostela, pero el cual, después de investido de báculo y anillo no llegaría a ser consagrado porque el arzobispo compostelano don Bernardo se negó a hacerlo, lo que le costó la renuncia a la sede arzobispal, que aceptó el papa

16 Martin, J. L.: "Mérida medieval, señorio santiaguista". Revista de Estudios Extremeños. Tomo LII, Num. II. Badajoz, 1996, pgs. 487 a 495. 
Gregorio IX mediante bula de 13 de Febrero de 1237, en la cual la Curia romana se reservaba expresamente el derecho a proceder a la elección de nuevo candidato en el futuro para la sede episcopal de Mérida ${ }^{17}$.

Aunque al arzobispo le costó el puesto, sin embargo, consiguió frenar el intento de restauración de la sede en Mérida y el consiguiente peligro de que los compostelanos se viesen obligados a devolver la dignidad metropolitana a su sede originaria. Por ello, el arzobispo don Juan, con licencia del rey Fernando III, cedió a la Orden Militar la otra mitad de la ciudad de Mérida, con sus términos y rentas, lo que fue aceptado por el papa Alejandro IV el 11 de Mayo de 1255. Y así, mientras Mérida pasó a ser propiedad plena de la Orden de Santiago, el arzobispo se alejaba y olvidaba de este territorio extremeño, que seguía en gran parte en poder de los musulmanes, evidenciando que sus manifestaciones en pro de la reconquista por los cristianos había sido una cortina de humo para ocultar que lo único que pretendía era la conservación de aquellos derechos de Mérida que transitoriamente había recibido con anterioridad y sobre los que cimentó la pujanza de la sede compostelana.

\section{CONCLUSIONES}

La Orden de Santiago, en su dominio sobre la ciudad y gran parte del territorio de la actual Extremadura, sólo lo veía como una fuente de recursos económicos, y aunque construyó muchas iglesias, si embargo se oponía firmemente a que se establecieran congregaciones monásticas, por temor expreso a la influencia de los frailes sobre el pueblo llano, como se manifiesta en 1440 en las Actas Capitulares de la Orden ${ }^{18}$, cuando se prohibe el establecimiento de instituciones monásticas alegando que los frailes "se entremeten a aconsejar»; y como consecuencia el mapa de congregaciones monásticas en la Provincia de León de la Orden de Santiago (nombre de los territorios santiaguistas en Extremadura), es menos denso que el de los territorios de realengo colindantes, lo que supuso un importante déficit social para sus habitantes al disponer, no sólo de una menor presencia de frailes sino también no contar con los servicios asistenciales y culturales que ellos solian prestar.

En nuestra opinión, el mayor perjuicio que ocasionó este proceso en el que Mérida fue sacrificada por el arzobispado compostelano, fue que en Extremadura prosiguió la repoblación cristiana del territorio sin que se organizase la sociedad con una vertebración consistente ${ }^{19}$, pues en un trabajo sobre este asunto expuse

Camacho Macias, A.: La sede episcopal emeritense, obra cit. Pag. 263.

${ }^{8}$ BN. Manuscrito num. 83. Actas Capitulares. Cita tomada de Mario Góngora: "Régimen señorial y rural en la Extremadura de la Orden de Santiago en el momento de la emigración a Indias". Colonia, 1995, pg. 23.

i9 Ballesteros Diez, J. A.: "La invertebración de Extremadura en el Antiguo Régimen". Revista de Estudios Extremeños. Tomo LII, Num. II, Badajoz, 1996, pgs.627 a 645 
cómo las universidades castellanas se fundaron sobre las escuelas catedralicias de las sedes metropolitanas, $y$, si se hubiera restaurado esa dignidad eclesiástica en Mérida, Extremadura (que no ha tenido universidad hasta el último cuarto del s. $x \mathrm{x}$ ) habria contado con esa importante institución, que no sólo supondría una referencia cultural, sino que habria formado gentes que hubieran podido articular la sociedad en función de valores más elevados que los que sustentan las relaciones clientelares y caciquiles que fueron predominantes y crónicas en la región.

Por otra lado, también en el ámbito político quedó postergada Extremadura, pues la región no tuvo ninguna ciudad de voto en Cortes hasta el año $1650^{20}$, cuando las ciudades de Badajoz, Mérida, Plasencia, y Trujillo, y las villas de Alcántara y Cáceres compraron ese derecho privilegiado a la Hacienda Real para usarlo y ejercerlo mancomunadamente; pero ya en ese momento las Cortes estaban a punto de desaparecer de modo práctico como asamblea del reino, por lo que esa posibilidad de aproximación de los concejos extremeños a la persona del Rey apenas tuvo incidencia. Vinculada a esta falta de representación política estaba también la dependencia fiscal del territorio extremeño respecto a Salamanca, la ciudad de voto en Cortes a la que correspondía en los encabezamientos fiscales hacer el repartimiento y cobranza de impuestos sobre los extremeños, y hay muchos datos de cómo se hacian esos repartimientos de una manera poco equitativa en claro perjuicio de éstos. Pues bien, también en esta red de ciudades de voto en las Cortes castellanas se producía que aquellas que eran sedes arzobispales tenian el privilegio del voto en Cortes. Es decir, la no restauración de la sede emeritense supuso para Extremadura no contar con asiento en las Cortes de Castilla ni disponer de una universidad durante aquellos tiempos medievales y del Antiguo Régimen, circunstancias ambas de tal entidad que ellas encuentro la raiz de la marginación y retraso que esta tierra y sus gentes ha padecido secularmente, y que, de ninguna manera, ni en ningún momento, la Orden de Santiago pretendió aliviar.

La renovación historiográfica que se ha producido en España ha traído una mejor comprensión de muchos procesos que parecían definitivamente cerrados, y así, en relación a la fundación de la Orden de Santiago, José Luis Martín ${ }^{21}$ realizó en la década de los 60 un estudio sobre esos orígenes, pero su exhaustivo análisis documental no rebasó la literalidad de los textos documentales, que no testimonian las verdaderas intenciones del arzobispo de Santiago, y asi Mérida no tiene cita ni presencia alguna en todo el estudio; y tal estudio, en su planteamiento corresponde plenamente al "cómo" se produjo la formación de la Orden de Santiago.

El transcurso del tiempo y el avance de otras corrientes historiográficas, ha ido aportando una visión más amplia, comprensiva y profunda de ese proceso funda-

20 Ballesteros Diez, J. A.: «La compra por Extremadura del privilegio de voto en las Cortes de Castilla". Espacio. Tiempo y Forma (Revista de la Facultad de Geografía e Historia de la UNED). Serie IV (Historia Moderna). Num. 16. Madrid, 2003, pgs. 255 a 293.

2 Martin, J. L.: Origenes de la Orden de la Orden Militar de Santiago (1170-1195). Obra citada. 
cional de la Orden de Santiago, y el mismo José Luis Martín ha aportado nuevas luces en ese camino, pues ahora ya no nos basta con saber cómo se ha producido un hecho histórico, sino que aspiramos a saber qué es lo que se ha producido realmente, y por qué y para qué, y asi lo registra José Luis Martín en artículos, como el citado de la Revista de Estudios Extremeños ${ }^{22}$, o en obra generales de Historia Medieval de España ${ }^{23}$, en los que claramente expone cómo maniobró el arzobispo de Santiago para transformar la congregación de los fratres de Cáceres en la Orden de Santiago, y mediante algunas donaciones, conseguir asegurarse el dominio sobre la sede emeritense una vez que se reconquistase la ciudad, consolidando así la titularidad trasladada a Compostela.

Esta falta de vertebración de las comunidades de los territorios extremeños, se va a visualizar en alguno de sus aspectos, el de la vivencia de la religiosidad cristiana dentro de la disciplina de la Iglesia católica, cuando en el siglo XIX se produce la supresión de la jurisdicción exenta de la Orden de Santiago sobre el territorio de la antigua Provincia de León, desaparecida con la organización provincial de España de Javier de Burgos en 1833, al disponerse por el papa Pío IX ${ }^{24}$, en su bula Quo gravius, de 14 de Julio de 1873, en la que se daban instrucciones ejecutivas para que pasaran al obispado de Badajoz las parroquias santiaguistas ubicadas en esta provincia, y que no fueron aceptadas por las parroquias de Mérida, Azuaga y Llerena, produciéndose un conflicto, al que se calificó como cisma, que tuvo vigencia hasta el año 1875.

Esta es, pues, la historia de una gran frustración en lo que respecta a Mérida y, consecuentemente, para lo que luego fue Extremadura; también es la historia de una impostura, pues la presencia y acción del arzobispo de Santiago en este fragmento del gran proceso que fue la Reconquista, no fue nunca una acción épico religiosa, ni estuvo motivada por la defensa de la espiritualidad cristiana, o de la civilización hispana, ni siquiera una colaboración para las fuerzas reales, pues en cuanto consiguió sus propósitos abandonó los campos de batalla; sólo fue una operación de mantenimiento de unas dignidades conseguidas precariamente y que consiguió mantener. tada.

"Martin, J. L.: "Mérida medieval, señorio santiaguista". Revista de Estudios Extremeños, obra ci-

3 Martin, J. L.: Manual de Historia de España. Tomo II. La España Medieval. Madrid, 1993.

${ }^{24}$ Camacho Macias, A.: La sede emeritense y su proyección histórica. Obra citada. Pag. 267. 